\title{
Chain accessories materials innovation use in dresses
}

\author{
Wan jing ${ }^{1, a}$ \\ ${ }^{1}$ Jiangxi Institute of Fashion Technology, Jiangxi, Nanchang, 330201 \\ a271776626@qq.com
}

Keywords: Women dress; Clothing; Chain accessories; application

\begin{abstract}
Chain accessories materials is one of the important elements of the design of clothing, is the unity of function and aesthetics. Reasonable skillfully use chain material in ladies dress, can not only design the function structure of perfect dress model, at the same time also to display the cultural connotation of the dress, meet the needs of human emotions. In this paper, the chain material using in-depth study in dresses, excavating the connotation of the chain material, promote fashion designer to the further understanding of the chain accessories materials, expand the dress design thinking, rich lady dress design language.
\end{abstract}

\section{The introduction}

Chain material has always been more is to meet the requirements of functional, compared with the fabric in a subordinate position. But the contemporary society has is the age of consumers with high design sensitivity, puts forward higher requirements on ladies dress designing, the chain material is not simple foil or decoration, but the perfect unification of both functional and decorative. Even some large brand after a subversive design using the chain material to undertake the role of main ingredient, and successfully, which triggered a new perspective in the field of fashion design, led to the concept of the new materials, change the traditional materials of their respective original advocate complementary position.

\section{The type of chain accessories}

Chain accessories is one of the more common decorative accessories accessories, there are many types of it. Main have enriched the contents of the clothing, highlight the characteristics of the clothing, ascension temperament of clothing, and so on. With the improvement of technical level, processing capacity has increased, the chain fittings are more and more: a hand chain metal chains, chains of fabric and zipper cloth type, etc. Especially in recent years the fashion design industry pay more and more attention to material research and design, even the appearance of many new chain accessories material combination. Our common metal chain accessories are aluminum, copper, iron, silver, and even some HunGeJin material. Different metals have different texture, and dress collocation can present different personality characteristics. Of course, the resin material, nylon material, knitting materials, such as cortex chain accessories. Different styles of chain material gives the chain accessories new life, enrich the design language of clothing designer, at the same time also let the chain accessories blooming in ladies dress design unique charm.

\section{The classification of the dresses}

Lady dress compared with men's dress, no matter from style, modelling, colour decoration, fabric accessories is more rich and colorful, it become material and women's clothing, the main design window. Ladies dress characteristic is close-grained, showing skin at night in the day, and evening dress use flash fabric and accessories. Lady dress is mainly depending on the wearing time, occasion, divided into dress, evening dress, wedding dress, cocktail parties and other species.

Dress is the formal dress to attend social activities during the day, such as the opening ceremony, banquet, wedding, garden, formal visit to the occasion to wear with the dress. Evening dress form has two kinds: one kind is the traditional evening, form is more low-cut, dew shoulder, back, waist and close-fitting dress, suitable for high-grade, with security occasion; Is a modern evening dress, be particular about the change of the style and color, with a sense of bold innovation. The style of 
the wedding dress according to the design, can be divided into western-style wedding dress with Chinese style wedding dress. Western-style wedding dress western-style wedding dress on the shape, color, fabric has the established rules. On modelling is X more fit dress, the front piece with the princess line, after a dozen provinces, tiered skirt waist do processing, in the form of dress pattern can have cascading. Dress, neck, waist and bottom hem can design according to the need to acquire similar knot, lace decoration, to show the modelling of wedding dress, skirt inside with a nylon mesh, silk material such as mesh, nylon cloth, gauze do bustle. Chinese bride's wedding dress is given priority to with the traditional short coat dress or qipao, modelling is of cultivate one's morality more suitable size, with Chinese style the style of the collar, loop, with strong Chinese traditional characteristics.

\section{Chain accessories used in dresses}

Dress design has its specific cultural background and connotation, for every designer is very challenging. Only on the basis of thorough different dress can truly be ladies dress design. Ladies dress design has many particular style needs to match specific clothing accessories to highlight its characteristics, the use of chain accessories at this time will need to merge in special accessories and with specific deserve to act the role of perfect collocation, otherwise too abrupt, easily backfire.

Chain accessories line performance. Chain accessories attribute is a line, line change is one of the important means of clothing design. Outside the clothing line can be in the form of contour shape wire, cut wire, provincial highway, pleated lines, decorative lines, and fabric line design, etc. Clothing forms of beauty nowhere not reveal qualification of creativity and expression. Chain accessories as important line carrier, in different dresses design also has the vital significance. As shown in figure 1, the four models in different line feeling dress gives a person the feeling completely different temperament, left the first female model of chain adopt the method of diagonal lines on the dress design, give a person the sense of a brisk, lively, very accord with the temperament of the model itself. Second from the left female model chain accessories adopt linear design method gives a person the feeling of peace settlement, make model looks more dignified and beautiful. Left the line of the third female model dress mainly curve gives people a warm feeling, liquidity lines also make the whole dress sense of rhythm. Chain on the fourth from the left female model dress accessories line is bold long straight line, give a person the sense of the atmosphere, bright and clear. Visible line feeling can highlight different people different temperament and different emotional experience to the person. The use of lines in different occasions to meet the particular atmosphere.

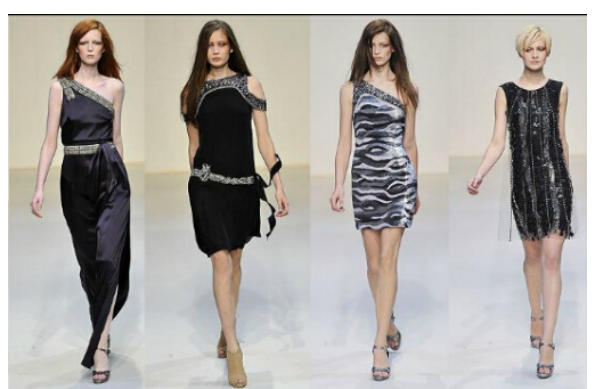

Fig.1 Different line of dress

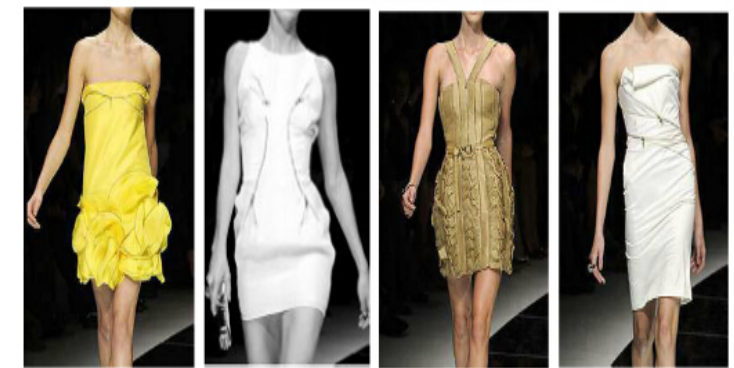

Fig. 2 The chain of materials is different dress

The adornment of the chain accessories. Chain of perfect combination of decorative and functional parts in use is also an important in the design of dress, the dress design in figure 2, has a good performance in its chain accessories also have the effect of the provincial road except for decoration. Horizontal, vertical, oblique to the chain of provincial roads can become an extension of the fabric, clothing between loose and tight wander freely, make the dress more flexibility. Figure 2 on the left side of the first models wearing the dress there are two parts to use zipper line design, the structure of the chest line break the routine to horizontal segmentation, waist province amount to the position of the chest chain accessories transfer, using the size of the amount of the zipper opening and closing to control the province. At the skirt with a strong sense of the zipper and fold without 
rules, curling into dynamic skirt, sprocket as the edge of the skirt line decoration highlights the administrative levels feeling of the skirt, mutual echo, line with chest zipper structure harmony. On the left side of the second model is wearing a white dress, metallic chain accessories added mechanical quality of a material is more in the future, but also broke the simple but elegant white feel more naughty feeling to the person. The location of the princess line installed the chain accessories, using chain accessories in the chest and waist to create free open space, the modelling of garment body varies opening and closing of the zipper, the princess line line is obtained by the adornment of the sprocket reinforcement, highlights the female's curve. The whole dress sexy in the adornment of the zipper, mature, concise. On the left the third model the outstanding performance of the chain accessories in the garment body. Straight line vertical segmentation although drab, strengthen the divider chain accessories to join, however, teeth and metallic chain and fabric form bright contrast. Opening in front of the appropriate use of zipper closure function, eliminates the trouble of invisible zipper side or back. On the left side of the fourth model in the dress chest waist across department USES the oblique two zipper design, horizontal form unusual clothing structure, breaking the traditional garment body split. Zipper open and close direction on a once, break the clothing color and style of monotonous, make dress full of dynamic.

The functional performance of the chain accessories. Change clothes outside contour is a wonderful chain accessories function. Through close clothes made of the zipper is clever organs, the bitter fleabane bitter fleabane coat can suddenly become tight, type A skirt can become A professional skirt, bell bottoms can be turned into A pencil pants, you will be surprised A little authority can make the same dress present A totally different style, surprise.

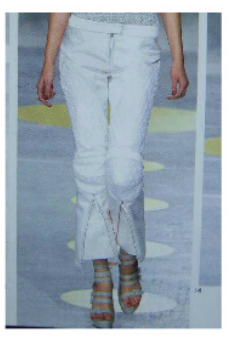

Fig.3 Different dress zipper material
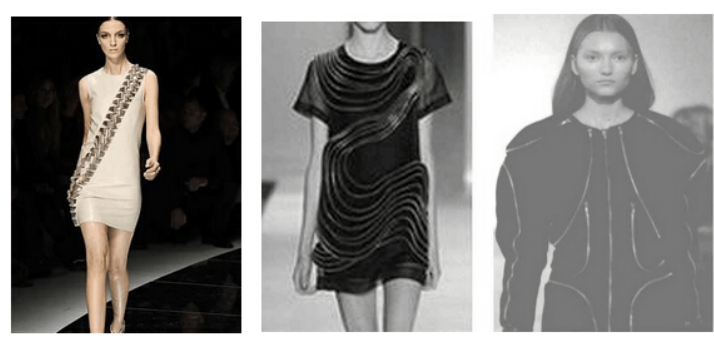

Fig. 4 Chain of the dress

Figure 3 on the left side of the first model under knee pants zipper design position the edge of the pants this design can complete from flares to the transformation of the foot trousers. Designers have the zipper design on both sides of the position in front of the lower leg rather than design in, highlight the adornment of the zipper, and form echo relationship with pants on the door of the zipper. On the left side of the second model is wearing a dress sense is cortex, the combination of leather and metal zipper handsome generous intuitive feelings to the person. Zipper throughout the left half of a skirt, zipper opens, the thigh, let the clothes appears more sexy. Zip on let the dress more fit body, also can present the wearer the curve of waist and buttock leg of women. Dress design in addition to highlight female bodies need to highlight female character more. Especially for a new era of women, the personality of dress design will be more attractive to them.

Figure 4 on the left in the first model using boast large zipper teeth oblique segmentation as the surface of a garment decorative elements, hard texture, and three-dimensional visual effect, make simple dress immediately hale and hearty, personality. On the left side of the second model dressed in a black dress with zipper unilateral form stereo modelling, metal chain tooth arrangement twists and turns, winding like a flowing water has a strong sense of rhythm, enrich the clothing surface fabric, and metallic chain accessories and black fabric to form bright contrast, give a person strong visual result. The left the third model wearing clothes gives people a feeling of strong sense of construction and the future, praised the structure of the line make clothing looks very kind, all the lines to structure are made of metallic zipper, the zipper line to the limit.

\section{Conclusion}

In this paper, the detailed analysis of all kinds of chain accessories materials, and its performance 
in all kinds of dresses. Chain accessories are all clothing accessories materials used in the clothing design is relatively wide and ordinary a accessories material. Further study of the chain accessories application in the dress of the direct purpose is to understand the charm of the chain material, understand the chain material is how to enhance the overall temperament of the dress, how to make different character of clothing design, how to make the parts material perfect fusion in the design of dress, to show the most perfect design works. Under the background of promoting innovation of contemporary clothing market more we need to settle, lay a solid knowledge of fashion design, a thorough investigation from all parts of the clothing, independent innovation, whether it's a gadget or a material or a way of cutting is worth deeply mining study, innovation can be powerful and unconstrained style but also need to be down-to-earth.

\section{Reference}

[1] Wei jing; Wei Jing; Sun Li. Taking unconventional materials application in the clothing modelling [J]. Journal of textile, 2014, (6).

[2] Xiang xuan. Introduction to how to realize the clothing material in the design of innovative applications [J]. Journal of art tasting, 2016 (6).

[3] Shaohua Chen. About metal material application in the clothing design research [D]. Dalian university of technology, 2012 (3). 